\title{
Measuring Efficiency Growth Rate in the Pre and Post Deregulation Periods: Wireless Mobile Phone Technology on Healthcare Delivery in Nigeria
}

\author{
Onochie Jude Dieli ${ }^{1}$ \\ Prairie View A\&M University, Prairie View \\ Gbolahan Solomon Osho \\ Prairie View A\&M University, Prairie View \\ Emmanuel Opara \\ Prairie View A\&M University, Prairie View \\ Modupe Ojumu \\ Prairie View A\&M University, Prairie View
}

\begin{abstract}
This study investigates how marginal impact differential of the availability of wireless mobile phone technology in the health industry has increased the efficiency growth rate of healthcare delivery in Nigeria. It divided the period of study into two - pre and post deregulation periods and compared the econometric coefficients of the regression equations. Using time series data of life expectancy rate as a proxy for efficiency growth rate, simple death rate, phone dependence rate, phone subscription rate variables and other explanatory variables in running simple baseline econometric regression models; the research find increased efficiency growth rate in health care delivery in post deregulation period than in pre deregulation period. The greater availability of mobile telephony technology decreased death rate in post deregulation period than in pre deregulation period by increased availability of health information in Nigeria.
\end{abstract}

Keywords: Deregulation, healthcare services, wireless mobile phone technology, economic growth,

\section{Introduction}

The deregulation of Nigeria's telecom industry leads to an intensive and extensive adoption of mobile phone technologies in virtually all sectors of the economy. The Internet is a component part of mobile phone technologies (O. Dieli et al 2019). This is generally believed to break barriers of entry to any industrial sector (The Economist, September, 2000). It also enriches entrepreneurs and employees with new knowledge which leads to innovation, efficiency and an increase in productivity. Freund and Weinhold (2004) argue that it is cheaper to start a business venture online than to establish conventional stores or offices.

In the study "Empirical Estimation of the Impacts of Wireless Mobile Phone Technology in the Diffusivity of Technologies and Productivity Growth of the Nigeria's Economic Sectors" published by Journal of Economics and Development Studies: American Research Institute for Policy Development; December 2019, Vol.7 No. 4, pp. 27-37 by Onochie Jude Dieli et al, it is found that the marginal impact of mobile phone technology diffusion of technologies is higher in industries that are less - dependent on telecom technology(example Health and Agriculture) before the advent of wireless mobile phone technologies than those that are more - dependent (example Post \&Telecommunication and Media).

In the same study, Nigeria's economic sectors are categorized into seventeen industriesusing ISIC and NAICS industry classification systems at 2- digit and 2, 3, 4-digit respectively. The period observed is 1999 to 2018. Data are homogeneously collated mainly from Nigerian institutions and a few international organizations. Below are the table and figure showing some of the findings of the study.

\footnotetext{
${ }^{1}$ Funding Source: The Ryoichi SasaKawa Young Leaders Fellowship Fund Nippon Foundation Tokyo Japan sponsored and provided the funding for the study at Howard University, Washington DC USA
} 
Table 1. All Industry Average Dependence Rate and Marginal Impact

\begin{tabular}{lll}
\hline Industry & Dpn & Marginal Impact \\
\hline Health & 0 & 0.083 \\
Agriculture & $3.21 \mathrm{E}-06$ & $8.30 \mathrm{E}-02$ \\
Oil \& gas & $2.08 \mathrm{E}-05$ & $8.30 \mathrm{E}-02$ \\
Water Resources & 0.00032 & 0.08297 \\
Solid Mineral & 0.00133 & 0.08289 \\
Electricity & 0.00337 & 0.08272 \\
Education & 0.01196 & 0.08201 \\
Finance \&Insurance & 0.01274 & 0.08194 \\
Construction & 0.01987 & 0.08135 \\
Manufacturing & 0.0225 & 0.08113 \\
Wholesale/Retail & 0.0328 & 0.08028 \\
Public ADM/Defense & 0.04307 & 0.07943 \\
Transport & 0.0449 & 0.07927 \\
Real Estate & 0.06425 & 0.07767 \\
Services & 0.2216 & 0.06461 \\
Post \&Telecoms & 0.39906 & 0.04988 \\
Media & 0.63913 & 0.02995 \\
\hline
\end{tabular}

Figure 1. Wireless Mobile Phone Technology Marginal Impact by Industry

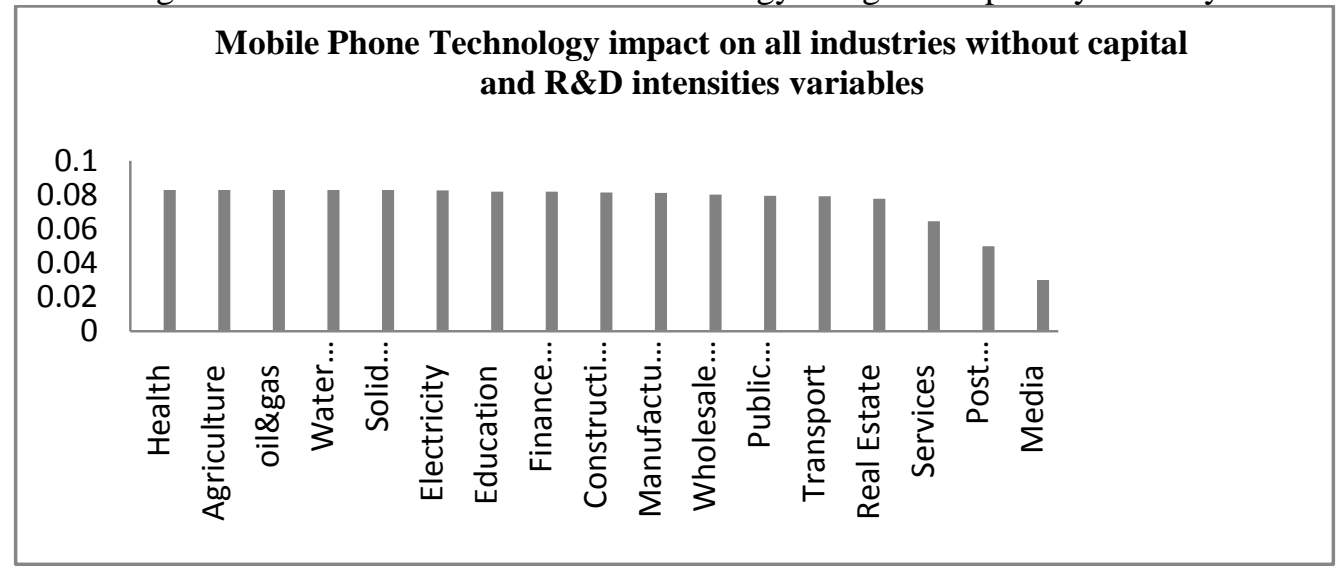

The health industry has the highest marginal impact among high and low capital intensive industries in Nigeria. Itis, therefore, relevant to study and measure how this marginal impact differential has translated into efficiency growth in healthcare delivery in Nigeria. The periods of interest are the pre and post telecom industry deregulation. This research tries to answer the question: does availability of wireless mobile phone technology in the health industry in Nigeria increase efficiency growth rate in healthcare delivery in the post deregulation period than in pre deregulation period by increasing or improving the life expectancy rate in Nigeria? This research paper also answers the question: does the availability of wireless phone technology decreases death rate in Nigeria in the post deregulation era of the telecom industry than in the pre -deregulation period?

\section{Prior Literatures}

It is a well-known fact that sub-Saharan Africa belongs to the underdeveloped part of the global community. As a result, communication was a problem before the advent of wireless mobile phone technology. Post and telecommunication using mail letters and analog technology using underground cables were the only means of communication both domestically and otherwise. Nigeria is the most populous African Nation with a population of approximately 200 million people (UN Digest, 2018, Nigerian Office of Statistics, 2018). After deregulation of telecom industry in 1999 as a result of the availability of wireless mobile technology; Mobile phones become widely and easily 
accessible. Cellular phone subscription rate per 100 people was 1 in 2002 and it increased to 88 in 2018(O J Dieli et al (2019).

The above paper argues that the availability of wireless technology helps to reduce the cost of learning and implementing world technology frontier in all sectors of the Nigerian economy and thus that it promotes smoother transfer of technology from technologically-advanced countries to Nigeria and brings significant growth in the economy as a whole. The study finds the Nigerian health sector as the sector with the highest marginal impact from the availability of the wireless mobile phone technology. This implies greater transformation of the sector in efficient service delivery(healthcare), research and sector efficiency growth.

There have been other pilot studies in other Sub-Saharan African countries on the impact of mobile phone technology on the efficiency growth in the healthcare delivery in a few Sub Saharan Africa states. They are SMS based messaging system for improved disease management. The initial resultsin the area of medication adherence among patients being treated for HIV and/or tuberculosis (TB) display efficiency and are promising (Barclay E., 2009). In addition, SIMpill is a pill dispensing system that embeds a SIM card in a small pill bottle, which registers and sends an SMS text to a central server each time the bottle is opened(ibid). Each text message is stamped and has a unique identifier linked to the patient's mobile phone number. If the central server does not receive text messages before a preset time, a reminder text is automatically sent to the patient's mobile phone. If there is no response, an alert is then sent to the patient's healthcare provider who can follow-up directly with the patient. A SIMmed pilot showed compliance rates of $90 \%$. This shows efficiency growth compared with the period of non-availability of wireless mobile phone technology.

In addition to direct communication and support for patients, a number of Mobile Health applications have been designed as tools to increase community health worker (CHW) access to health information, decision making, and/or logistical support. For example, SMS-based communication and professional networking to support CHWs were studied in rural areas of Malawi (Lemay NV and etal, 2012). The authors employed a mixed methods approach to determine the frequency of SMS use, the most common reasons for use, and CHW feedback on the extent to which SMS capabilities facilitated and improved the quality of medical care that they could provide. Communication costs and efficiency were compared between one geographic area with SMS capabilities and two areas of similar demographics that did not have SMS or other cell phone service. In this study, CHWs most often used SMS to report medical supply shortages, followed by texts to obtain or communicate general information, and then by texts about patients with emergencies. The average cost per communication was about five times less expensive using SMS than in areas without SMS service. This translates to better and efficient healthcare delivery.

In another study in Nigeria, Salihu I Dasuki and Efpraxia D Zamani (2019); have looked into how pregnant women in the city of Jos, Plateau State, Nigeria, use the mobile phone in understanding the effectiveness of mobile phone technology in maternal health in Nigeria.The study findings indicate that mobile phones have development outcomes and implications. It goes beyond being a tool for accessing maternal health but helps in improving pregnant women's maternal health literacy and information acquisition abilities. They now know the benefits of prenatal services which enhances a healthy lifestyle amongst them. They can manage minor health illness during pregnancy. This has an advantage of reducing pregnancy risks and symptoms associated with maternal morbidity and mortality. This increases life expectancy and hence reduces death rate.

\section{Method}

This study measures efficiency growth rate in healthcare delivery in Nigeria using life expectancy rate as dependent variable. The period of study is divided into pre and post deregulation periods. This is ten years before deregulation of the telecom sector in 1999 and ten years after respectively. These time periods are long enough to derive finite analysis on the impact of the increasing availability of wireless mobile technology on healthcare delivery in Nigeria. Before the advent of wireless mobile phone technology, Nigeria was using the cable phone technology which had high fixed cost and very expensive to operate. The emergence of the wireless mobile phone technology drastically reduced the cost of doing business in the telecom industry in Nigeria. The spillover effect led to the adoption of wireless mobile phone technology in all the sectors of the economy with marginal impact that increased among industries that were less dependent on telecom technology. In the previous study cited above, health sector shows greatest marginal impact. This has created the desire for verification and confirmation of efficiency growth in healthcare delivery in Nigeria as a result of this marginal differential. 
Efficiency in healthcare delivery is proximate to increasing life expectancy. This research compares periods of pre and post deregulation of the telecom sector for the effect of greater availability of wireless mobile phone technology on efficiency growth rate in healthcare delivery. With efficiency (life expectancy rate) as the dependent variable, Mobile phone subscription rate (Mps rate or PS rate), sector dependence on wireless mobile phone technology(dpn), education level of the population (literacy rate), number of doctors in the country per 1000 people, Hospital bed per 1000people, industry expenditure on research as a proportion of GDP are the predictors. This research also runs the same regression for death rates in the pre and post deregulation periods with same predictors in order to answer the second research question.

\section{Baseline Econometric Specification}

The model below is constructed to provide answers to stated research questions. Let's define the Efficiency of healthcare delivery (life expectancy) at time $t$ as

fort $=1,2,3 \ldots \mathrm{T}$, and let $y_{t}^{*}$ be its growth rate.

$$
Y_{t}^{*} \equiv \text { Life Expectancy Rate } \text { t }_{\mathrm{t}}
$$

The model is written as:

$$
\begin{aligned}
& y_{t}^{*}=\alpha+\beta_{1} \mathrm{mph}_{\mathrm{it}}+\beta_{2} d p n_{i t}+\beta_{3} \mathrm{dpn}_{\mathrm{it}} \times \mathrm{mph}_{\mathrm{it}}+\beta_{4} \mathrm{gr}_{\mathrm{g}} \mathrm{d}_{\mathrm{it}}+\beta_{5} \mathrm{edu}_{\mathrm{it}}+\beta_{6} \mathrm{NGHng}_{\mathrm{it}}+ \\
& +\beta_{7} \mathrm{NDng}_{\mathrm{it}}+\beta_{8} \text { GDP per capita }{ }_{\mathrm{it}}+\varepsilon_{\mathrm{it}}(2)
\end{aligned}
$$

for $i=1$, where $y_{t}^{*}$ is the efficiency growth rate of healthcare delivery, $\alpha$ is the health industry fixed effects, mph is the mobile phone subscription rate per 100 persons, dpn is the dependence of health industry on mobile phone technology, the coefficient of interest is the $\beta_{3}$ (it shows relationship between life expectancy and the interaction effect of mobile phone subscription rate and sector dependence on telecom technology)andgr\&dis the health industry expenditure including research by government as a percentage of GDP, eduis the proportion of Nigerian population with basic education that is literacy rate at time, NGHng is the number of General Hospital in Nigeria(proximate by hospital beds per 1000people) and they are operated by either States or Federal governments of Nigeria, NDng is the number of medical doctors per 1000 people in Nigeria and $\varepsilon_{i t}$ is the error term (residual).

The dependence on telecom technologies is the share of expenditures on telecommunication out of total expenditure on intermediate inputs. Mobile phone subscription rate is the mobile subscription per 100 persons in Nigeria. The interaction term of mobile phone subscription rate and dependency on mobile phone technology shows how the availability of mobile phone technology and the health industry current level of technology adoption interact to impact on healthcare delivery measured by growth of life expectancy rate. GR\&D represents the expenditure on health sector including research as a percentage of GDP.

In order to find how the new mobile phone technology impacts on life expectancy in the pre and post deregulation periods,Partial derivative of the baseline econometric equation above is taken with respect to mobile phone subscription rate and the resultant equation is as follows:

$$
\frac{\partial y_{t}^{*}}{\partial m p h_{t}}=\beta_{1}+\beta_{3} d p n_{t}
$$

Then substitute values for $\beta_{1}, \beta_{3}$ and dpn for the years, and compare the magnitude of the impacts for the two periods. In comparing the two periods, this study substitutes the dpn values for the years of pre and post deregulation periods in the equation of the partial derivative above and analyze the magnitude of differences in wireless mobile phone technologies marginal impacts over the periods.

The second econometric model that estimates availability of mobile phone technology effects on death rate is written below with the same predictors as in efficiency of healthcare delivery. Repeat the same mathematical procedure for the magnitude of the marginal impacts on death rate for the two periods and compare results as done above.

$\Omega=$ death $_{\text {rate }}$

\section{Measures and Data}

$$
\begin{array}{r}
\Omega_{\mathrm{t}}=\alpha+\beta_{1} \mathrm{mph}_{\mathrm{t}}+\beta_{2} \mathrm{dpn}_{\mathrm{t}}+\beta_{3} \mathrm{dpn}_{\mathrm{t}} \times \mathrm{mph}_{\mathrm{t}}+\beta_{4} \mathrm{gr} \& \mathrm{~d}_{\mathrm{t}}+\beta_{5} \mathrm{edu}_{\mathrm{t}}+\beta_{6} \mathrm{NGHng}_{\mathrm{t}}+\beta_{7} \mathrm{NDng}_{\mathrm{t}}+ \\
+\beta_{8} \mathrm{GDPpercapita}_{\mathrm{t}}+\varepsilon_{\mathrm{t}}
\end{array}
$$

Using ISIC and NAICS industry classification systems at 2- digit and 2, 3, 4-digit respectively, Nigeria's economic sectors are categorized into seventeen industries. The period of focus is pre and post deregulation period of the telecom industry. Telecommunication sector was deregulated officially in 1999. In this research, data are homogeneously collated mainly from Nigerian institutions and a few international organizations. 
There are other industry classification codes like Global Industry Sector Codes which might classify Nigeria sectors better but due to the fact that my dependence variable data is based on US data, it is statistically wise to use the NAICS criteria. The major limitation of this study is that the dependence rates on mobile phone technology of industry sectors are calculated based on the US data due to the non-availability of such data for Nigeria. The intuition behind the use of US data for other countries is based on the assumption that economic sectors behave alike globally. For example, Jebershan and Kochanova (2013) applied the US mobile phone technology dependence rates to the European industry sectors. This study applies the US rates to Nigeria health industry. However, I have to admit that there is a possibility that the US industry structure is different from that of Nigeria.

Table 2. Correlation Matrix

\begin{tabular}{|c|c|c|c|c|c|c|c|c|c|}
\hline & $\begin{array}{l}\text { Literacy } \\
\text { Rate }\end{array}$ & $\begin{array}{l}\text { Hospital } \\
\text { Bed } \\
\text { rate } \\
\text { per } \\
1000\end{array}$ & $\begin{array}{l}\text { GDP } \\
\text { growth } \\
\text { rate }\end{array}$ & $\begin{array}{l}\text { PSrate } \\
\text { by } \\
100 \\
\text { People }\end{array}$ & $\begin{array}{l}\text { Life } \\
\text { Expectancy } \\
\text { Rate }\end{array}$ & $\begin{array}{l}\text { Death } \\
\text { Rate }\end{array}$ & $\begin{array}{l}\text { Physician } \\
\text { Per } \\
1000\end{array}$ & $\begin{array}{l}\text { Gvtspdng } \\
\text { on } \\
\text { Health }\end{array}$ & $\begin{array}{l}\text { DPN } \\
\text { rate }\end{array}$ \\
\hline $\begin{array}{l}\text { Literacy } \\
\text { Rate }\end{array}$ & 1 & & & & & & & & \\
\hline $\begin{array}{l}\text { HospitalBed } \\
\text { rate } \\
\text { per1000 }\end{array}$ & -0.234 & 1 & & & & & & & \\
\hline $\begin{array}{l}\text { GDPgrowth } \\
\text { rate }\end{array}$ & $-.403^{*}$ & $.555^{* *}$ & 1 & & & & & & \\
\hline $\begin{array}{l}\text { PSrate } \\
\text { by100 } \\
\text { people }\end{array}$ & $.467^{*}$ & 0.264 & 0.022 & 1 & & & & & \\
\hline $\begin{array}{l}\text { Life } \\
\text { Expectancy } \\
\text { Rate }\end{array}$ & $.603^{* *}$ & 0.198 & -0.062 & $.982^{* *}$ & 1 & & & & \\
\hline $\begin{array}{l}\text { Death } \\
\text { Rate }\end{array}$ & $-.566^{* *}$ & -0.227 & 0.032 & $.988^{* *}$ & $-.998^{* *}$ & 1 & & & \\
\hline $\begin{array}{l}\text { Physician } \\
\text { Per } \\
1000\end{array}$ & -0.065 & $.454^{*}$ & 0.127 & $.563^{* *}$ & $.521^{* *}$ & $.538^{* *}$ & 1 & & \\
\hline $\begin{array}{l}\text { Gvtspdng } \\
\text { OnHealth }\end{array}$ & -0.119 & $.387^{*}$ & 0.140 & $.736^{* *}$ & $.654^{* *}$ & $-684^{* *}$ & $.627^{* *}$ & 1 & \\
\hline DPNrate & $.731^{* *}$ & -0.064 & -0.330 & $.643^{* *}$ & $.744^{* *}$ & $-718^{* *}$ & $.413^{*}$ & 0.352 & 1 \\
\hline
\end{tabular}

\section{Industries Telecoms Technologies Dependence Rate}

A measure of industries' dependence on telecommunication hereafter called telecom dependence is the share of expenditures on telecommunication out of total expenditure on intermediate inputs as defined in Jerbashian and Kochanova (2013). The variable can reflect the industries' current state of the mobile technology adoption and therefore it is used as an estimate of availability of mobile phone technology in the health industry. Due to nonavailability of this kind of complex data in Nigeria, the US data set is adopted from the US Bureau of Economic Analysis (BEA) Use Tables/Before Redefinitions/Producer Value ${ }^{2}$ for the pre and post deregulation periods.

It is calculated by deriving the ratio of the share of expenditures on telecommunication out of total expenditure on intermediate inputs for each industry. The use of the US data for Nigerian economic sectors is based on the assumption that sectors behave alike worldwide.

2Use of commodity by industries valued at producer's prices: 1997-2013- 15 industries (XLSX),

71 industries (XLXS), 2007-389 industries (XLSX) from Bureau of Economic Analysis web

sitehttp://www.bea.gov/industry/io_annual.htm 
Jerbashian and Kochanova (2013) also estimate dependence rates of industries in OECD (Organization for Economic Co-operation and Development) countries using the U.S. data based on the same assumption.

\section{Mobile Phone Subscription Rate for Nigeria}

The mobile phone subscription rate is calculated as mobile telephone subscribers per capita (per 100 persons) in Nigeria for the pre and post deregulation periods. The data is obtained from World Bank databases, 2019. The variable can capture the progress of the latest wireless mobile telephone technologies in Nigeria for the period of study.

\section{Government spending in healthcare Industry}

This is the expenditure by government on health industry on research, development and innovation as a percentage of GDP. This variable is derived from CBN Bulletin, 2018. The data represent the total expenditure on health sector (R\&D) by Government as a percentage of GDP. The period covered is the pre and post deregulation periods. Based on the earlier research cited above, health sector falls into high R\&D intensity industry. This outcome is similar to EU $\mathrm{R} \& \mathrm{D}$ intensity classification in Survey on industrial $R \& D$ Investment Trends European Commission JRC/DG RTD (2013).

\section{Life Expectancy Rate in Nigeria}

The global life expectancy at birth is 72.0 in 2016. For women, it is 74.2 and men is 69.8years. In African region, it is 69.8 for women and 61.2 for men in WHO African region. In WHO European region, it is 77.5 years and this translates to ratio of 1.3 between two regions. It is concluded by WHO that women live longer than men all over the World. Hong Kong has the highest life expectancy in the World with 81.8 years average life in 2019(WHO, 2019). In Nigeria, the average life expectancy is 54.5years and women live 55.4 years while men live 53.7years(WHO, 2019). This shows remarkable increase from the life expectancy of the 1970s and 1960's(WHO,2019). This study evaluates the role of wireless mobile phone technology in this development after deregulation.

Table 3. Pre Deregulation1990-1999 - Life Expectancy Results

\begin{tabular}{|c|c|c|c|c|c|}
\hline \multicolumn{6}{|l|}{ Coefficients $^{\mathrm{a}}$} \\
\hline \multirow[b]{2}{*}{ Model } & \multicolumn{2}{|c|}{ Unstandardized Coefficients } & \multirow{2}{*}{$\begin{array}{l}\text { Standardized } \\
\text { Coefficients } \\
\text { Beta }\end{array}$} & \multirow[b]{2}{*}{$\mathrm{t}$} & \multirow[b]{2}{*}{ Sig. } \\
\hline & $\mathrm{B}$ & Std. Error & & & \\
\hline (Constant) & 92.342 & 36.402 & & 2.537 & .085 \\
\hline LiteracyRate & -.850 & .652 & -.285 & -1.304 & .283 \\
\hline HospitalBedrateper1000 & -.023 & .020 & -.150 & -1.172 & .326 \\
\hline GDPgrowthrate & .004 & .003 & .177 & 1.416 & .252 \\
\hline PSrateby100peple & .051 & .007 & .797 & 7.468 & .005 \\
\hline Physicianper1000 & 3.742 & 1.832 & .171 & 2.042 & .134 \\
\hline GvtspdngonHealth & -.015 & .100 & -.030 & -.147 & .892 \\
\hline
\end{tabular}

a. Dependent Variable: Life Expectancy Rate

\section{Number of General Hospital and or hospital bed per 1000 people}

In Nigeria, there are public and private hospitals. The States and Federal governments in Nigeria own hospitals and some are designated as General hospitals for primary healthcare delivery in the states and the country. With tax payers' funds, healthcare services are subsidized by the governments. So, it is cheaper for the citizens to go and receive healthcare services in the public hospital than private hospitals that are profit oriented. The number of general hospitals is 33,303 and 20,278 primary health both rendering healthcare services in Nigeria(www.ncbi.nlm.nih.gov > pmc > articles > PMC3249694). Due to non-availability of times series data on number of hospitals in Nigeria, this study uses number of bed per 1000people in Nigeria to proximate it. The wireless mobile phone technology availability in the health sector in Nigeria increased with deregulation policy of 1999. 
Table 4. Post Deregulation 2000-2018- Life Expectancy Results

\begin{tabular}{|c|c|c|c|c|c|}
\hline \multicolumn{6}{|l|}{ Coefficients $^{\mathrm{a}}$} \\
\hline \multirow[b]{2}{*}{ Model } & \multicolumn{2}{|c|}{$\begin{array}{l}\text { Unstandardized } \\
\text { Coefficients }\end{array}$} & \multicolumn{2}{|c|}{$\begin{array}{l}\text { Standardized } \\
\text { Coefficients }\end{array}$} & \multirow[b]{2}{*}{ Sig. } \\
\hline & B & Std. Error & Beta & $\mathrm{t}$ & \\
\hline (Constant) & 38.137 & 4.056 & & 9.403 & .000 \\
\hline Literacy Rate & .149 & .060 & .273 & 2.493 & .032 \\
\hline $\begin{array}{l}\text { HospitalBedrateper } 10 \\
00\end{array}$ & -.400 & .286 & -.055 & -1.400 & .192 \\
\hline GDPgrowthrate & -.033 & .032 & -.044 & -1.047 & .320 \\
\hline PSrateby100peple & .064 & .006 & .708 & 10.338 & .000 \\
\hline Physicianper1000 & 1.135 & 1.058 & .051 & 1.073 & .308 \\
\hline GvtspdngonHealth & .074 & .285 & .016 & .260 & .800 \\
\hline DPNrate & 1.290 & 2.528 & .037 & .510 & .621 \\
\hline
\end{tabular}

a. Dependent Variable: Life Expectancy Rate

\section{Number of medical doctors per 1000 people in Nigeria}

Before independence of Nigeria from Britain, the ratio of physicians per 1000 people in Nigeria was small. In 1965, the ratio was .043 and in 2013 it rose to .383 and has been on the increase. This is attributed to the availability of western education and at times good governance. The ratio fluctuates from time to time. When the polity and the economy look good, people stay and do not migrate for greener pastures (brain drain). Many Nigerians are in the western hemisphere practicing as licensed physicians (World Health Organization's Global Health Workforce Statistics, OECD, supplemented by country data, 2013).

\section{Death Rate in Nigeria}

This is a measure of death per 1000 in a year. The death rate for Nigeria in 2018 was 11.97 deaths per 1000 people. This is 2.52 decline from 2017. The Nigerian death rate in Nigeria in 2017 was 12.274 deaths per 1000 people, a 2.46 decline from 2016 (WHO, 2018). This continuous decline in death rate is the basis of this research. Therefore, it is justifiable to verify the impact of the availability of wireless phone technology in death rate decline in Nigeria. This study investigates how the greater availability pf mobile phone technology helped in the reduction of death rate in Nigeria after deregulation.

Table 5. Pre Deregulation1990-1999 - Death Rate Results

\begin{tabular}{|c|c|c|c|c|c|c|}
\hline \multicolumn{7}{|c|}{ Coefficients $^{\mathrm{a}}$} \\
\hline \multirow[b]{2}{*}{ Model } & & \multicolumn{2}{|c|}{ Unstandardized Coefficients } & \multirow{2}{*}{$\begin{array}{l}\text { Standardized } \\
\text { Coefficients } \\
\text { Beta }\end{array}$} & \multirow[b]{2}{*}{$\mathrm{t}$} & \multirow[b]{2}{*}{ Sig. } \\
\hline & & B & Std. Error & & & \\
\hline & (Constant) & -146.988 & 90.506 & & -1.624 & .203 \\
\hline & LiteracyRate & 3.011 & 1.621 & .524 & 1.858 & .160 \\
\hline & HospitalBedrateper1000 & .066 & .049 & .223 & 1.355 & 268 \\
\hline & GDPgrowthrate & .001 & .007 & .028 & .173 & 874 \\
\hline & PSrateby100peple & -.051 & .017 & -.413 & -3.002 & .058 \\
\hline & Physicianper1000 & -5.862 & 4.555 & -.139 & -1.287 & .288 \\
\hline & GvtspdngonHealth & -.133 & .248 & -.140 & -.535 & .630 \\
\hline
\end{tabular}

a. Dependent Variable: Death Rate 
Table 6. Post Deregulation 2000-2018 - Death Rate Results

\begin{tabular}{|c|c|c|c|c|c|c|}
\hline \multicolumn{7}{|c|}{ Coefficients $^{\mathrm{a}}$} \\
\hline \multirow[b]{2}{*}{ Model } & & \multicolumn{2}{|c|}{ Unstandardized Coefficients } & \multirow{2}{*}{$\begin{array}{l}\text { Standardized } \\
\text { Coefficients } \\
\text { Beta }\end{array}$} & \multirow[b]{2}{*}{$\mathrm{t}$} & \multirow[b]{2}{*}{ Sig. } \\
\hline & & B & Std. Error & & & \\
\hline & (Constant) & 23.902 & 3.180 & & 7.517 & .000 \\
\hline & LiteracyRate & -.108 & .047 & -.264 & -2.308 & .044 \\
\hline & HospitalBedrateper1000 & .263 & .224 & .049 & 1.176 & .267 \\
\hline & GDPgrowthrate & .020 & .025 & .035 & .794 & .446 \\
\hline & PSrateby100peple & -.050 & .005 & -.737 & -10.323 & .000 \\
\hline & Physicianper1000 & -.792 & .829 & -.048 & -.954 & .362 \\
\hline & GvtspdngonHealth & -.078 & .223 & -.023 & -.349 & .735 \\
\hline & DPNrate & -.511 & 1.982 & -.020 & -.258 & .802 \\
\hline
\end{tabular}

a. Dependent Variable: Death Rate

\section{Proportion of Population that hasEducation (literacy rate)}

Education is measured as a stock variable which is the number of the population with a basic education (high school), divided by the total population of the country at time t using data obtained from Nigeria's Office of Statistics (2019), Abuja, Nigeria. The data for high school educational level is obtained from UNESCO PARIS 6 - 7 September 2012 Action Plan Nigeria and Federal Ministry of Education, Nigeria, 2013 and World Development Indicators(World Bank,2019).

\section{GDP per capita growth rate for the Pre and Post deregulation periods}

In most countries, a naïve measure of economic growth rate would be the per capita GDP growth rate. GDP growth rates are collected and this variable can represent the rate at which output per person grows in Nigeria, which when aggregated, indicate the total economy's growth trend. The data set used are Nigeria's Office of Statistics, Abuja.

\section{Results and Findings}

In table 2, the correlation matrix shows that correlation coefficients are significant at 0.01 and 0.05 levels of significance. So, linearity is established between the regressors and regressand. There is no noise and the test is good and efficient. In table 3 and 4, the linear regression having life expectancy as dependent variable in the pre and post deregulation periods showed that dependence rate on telecoms in pre deregulation period was zero. Some of the explanatory variables like literacy rate, hospital bed per 100 persons showed incoherent behaviour while others like GDP growth rate, phone subscription rate and physician per 1000 people have positive standardized coefficients which showed positive impact on life expectancy growth rate. However, the effect is not as much as the coefficients of the variables in the post deregulation period. In the post deregulation period, the standardized coefficients of the dpn (telecom dependence rate) is positive which implies increase in the mean of the life expectancy variable and so is the phone subscription rate with positive standard coefficient of .708. It is significant.

The result shows that increase in mobile phone subscription increases efficiency in healthcare delivery. Government spending on health, Physician per 1000 persons are all positive implying increase in the mean of life expectancy variable. The econometric results suggest that life expectancy mean rate increased with an increase in telephone dependency rate as well as phone subscription rate. The magnitude of the marginal impact differential on life expectancy rate is greater in post telecom deregulation period than in pre - deregulation period. The estimation is derived by substituting the Beta values of the partial differential equation and solving for the weights. The values of dpn in pre deregulation period was zero for the decade thereby leaving the weight to be equal to the value of Beta 1. This value is smaller than the weight of the post deregulation period because dpn has some positive values thereby making the total weight to be greater than the sum of the Beta 1. The outcome shows that the availability of wireless mobile phone technology positively impacted on the efficiency growth rate in the healthcare delivery in Nigeria by increasing life expectancy rate in the post deregulation period than pre-deregulation period.

Therefore, to answer the research question: does availability of wireless mobile phone technology in the health industry in Nigeria increase efficiency growth rate in healthcare delivery in the post deregulation period than in pre deregulation period by increasing or improving the life expectancy rate in Nigeria? The answer is in the affirmative. 
The availability of mobile phone technology brought ease of communication in health delivery system and this has enhanced increase in efficiency growth rate in the industry through increased life expectancy rate. Furthermore, the research question: does the availability of wireless phone technology decreases death rate in Nigeria in the post deregulation era of the telecom industry than in the pre-deregulation period.

The econometric results from the tables 5 and 6 show that before deregulation of the industry, the dependence rate of health sector on telecom was zero and phone subscription was very low. However, a remarkable decrease in death rate is observed in the post deregulation period compared to pre - deregulation periods. Death rate in pre deregulation period was in the increase while in post deregulation, it is declining till date perhaps due availability of health information made possible by wireless mobile phone technology.

\section{Conclusion}

There is no gainsaying the fact that implementation of deregulation policy in the telecom industry increased the availability of mobile phone technology in many sectors of the Nigerian economy. The health industry originally less dependent on telecom technology adopted mobile phone technology and increased efficiency in healthcare delivery in Nigeria in the period of post deregulation (ten years after).

\section{References}

1. Barclay E (2009), Text messages could hasten tuberculosis drug compliance. The lancet.2009;373(9657): 1516(PubMed) (Google Scholar)

2. Freund, C. L. and D. Weinhold (2004), "The effect of the internet on international trade". Journal of International Economics 62(1), 171-189.

3. Onochie Jude Dieli et al (2019), "Empirical Estimation of the Impacts of Wireless Mobile Phone Technology in the Diffusivity of Technologies and Productivity Growth of the Nigeria's Economic Sectors" Journal of Economics and Development Studies: American Research Institute for Policy Development; December 2019, Vol.7 No. 4, pp. 27-37.

4. Jerbashian and Kochanova (2013), "The impact of telecommunication technologies on competition in services and goods markets: empirical evidence". CERGE-EI

5. Lemay NV, Sullivan T, Jumbe B, Perry C P; Reaching remote Health workers in Malawi: Baseline assessment of a pilot Mhealth Intervention-Journal of Health Communication, 2012; 17(Supplement): 105-117 Google Scholar

6. Salihu Ibrahim Dasuki \&Efpraxia D Zamani (2019) “Assessing Mobile Phone use by pregnant women in Nigeria: a capability perspective" https://doi.org/10.1002/isd2.12092

7. World Bank, 2020www.ncbi.nlm.nih.gov > pmc > articles > PMC3249694

8. UN Digest, 2018, Nigerian Office of Statistics, 2018

9. World Bank (2019) World Bank, "Economic Indicator Data" Retrieved from http:// www.worldbank.org/WHO, 2018 